\title{
OPERATIONAL REMOTE SENSING SERVICES IN NORTH EASTERN REGION OF INDIA FOR NATURAL RESOURCES MANAGEMENT, EARLY WARNING FOR DISASTER RISK REDUCTION AND DISSEMINATION OF INFORMATION AND SERVICES
}

P.L.N. Raju ${ }^{a^{*},}$ K.K. Sarma ${ }^{a}$, Diganta Barman ${ }^{a}$, Bijoy Krishna Handique ${ }^{a}$, , Dibyajyoti Chutia ${ }^{a}$, S.S. Kundu ${ }^{a}$, Ramani Kr Das, Kasturi Chakraborty ${ }^{a}$, Ranjit Das ${ }^{a}$, Jonali Goswami ${ }^{a}$ Prathiba Das $^{\mathrm{a}}$, H. Suchitra Devi ${ }^{\mathrm{a}}$, Jenita M. Nongkynrih ${ }^{\mathrm{a}}$, Kuntala Bhusan ${ }^{\mathrm{a}}$, M. Somorjit Singh ${ }^{\mathrm{a}}$, P.Subhash Singh ${ }^{\mathrm{a}}$, Victor Saikhom ${ }^{\mathrm{a}}$, Chandan Goswami ${ }^{\mathrm{a}}$, Rocky Pebam ${ }^{\mathrm{a}}$, Arup Borgohain ${ }^{\mathrm{a}}$, , ,Rekha B. Gogoi $^{\mathrm{a}}$, N.Romeji Singh ${ }^{\mathrm{b}}$, Amaljit Bharali ${ }^{\mathrm{a}}$, , Dipima Sarma ${ }^{\mathrm{a}}$, Rosly Boy Lyngdoh ${ }^{\mathrm{a}}$, Partho Pratim Mandal ${ }^{\mathrm{c}}$, Mayuri Chabukdhara ${ }^{\mathrm{d}}$,

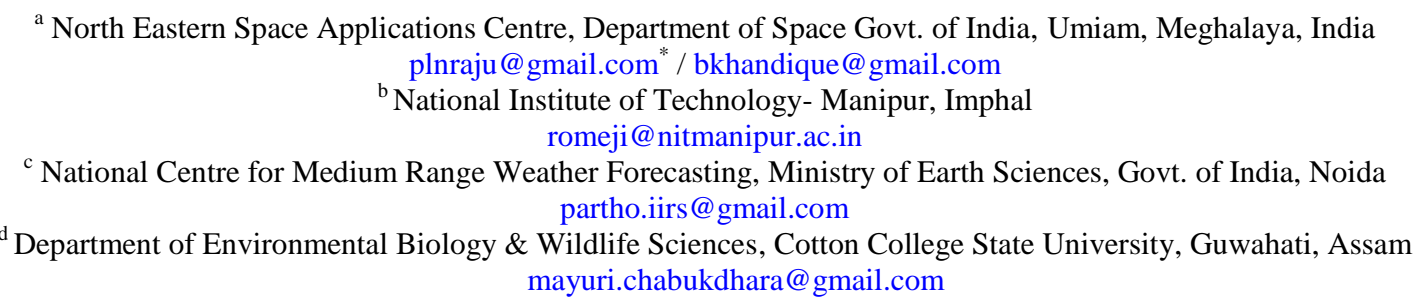

Commission VIII, ThS 2

KEY WORDS: Operational Remote Sensing, natural resources, disaster risk reduction, knowledge dissemination

\begin{abstract}
North Eastern Region (NER) of India comprising of eight states considered to be most unique and one of the most challenging regions to govern due to its unique physiographic condition, rich biodiversity, disaster prone and diverse socio-economic characteristics. Operational Remote Sensing services increased manifolds in the region with the establishment of North Eastern Space Applications Centre (NESAC) in the year 2000. Since inception, NESAC has been providing remote sensing services in generating inventory, planning and developmental activities, and management of natural resources, disasters and dissemination of information and services through geo-web services for NER. The operational remote sensing services provided by NESAC can be broadly divided into three categories viz. natural resource planning and developmental services, disaster risk reduction and early warning services and information dissemination through geo-portal services.
\end{abstract}

As a apart of natural resources planning and developmental services NESAC supports the state forest departments in preparing the forest working plans by providing geospatial inputs covering entire NER, identifying the suitable culturable wastelands for cultivation of silkworm food plants, mapping of natural resources such as land use/land cover, wastelands, land degradation etc. on temporal basis.

In the area of disaster risk reduction, NESAC has initiated operational services for early warning and post disaster assessment inputs for flood early warning system (FLEWS) using satellite remote sensing, numerical weather prediction, hydrological modeling etc.; forest fire alert system with actionable attribute information; Japanese Encephalitis Early Warning System (JEWS) based on mosquito vector abundance, pig population and historical disease intensity and agriculture drought monitoring for the region.

The large volumes of geo-spatial databases generated as part of operational services are made available to the administrators and local government bodies for better management, preparing prospective planning, and sustainable use of available resources. The knowledge dissemination is being done through online web portals wherever the internet access is available and as well as offline space based information kiosks, where the internet access is not available or having limited bandwidth availability.

This paper presents a systematic and comprehensive study on the remote sensing services operational in NER of India for natural resources management, disaster risk reduction and dissemination of information and services, in addition to outlining future areas and direction of space applications for the region. 


\section{INTRODUCTION}

North Eastern Region (NER) of India comprising of eight states with a geographical area of $262,230 \mathrm{~km}^{2}$ ( $8 \%$ of India's size); and a population of 45.6 million ( $3.1 \%$ of the total Indian population) considered to be most unique and one of the most challenging regions to govern due to its unique physiographic condition, rich biodiversity, disaster prone and diverse socioeconomic characteristics.

The remote sensing technology has been playing an important role in providing detailed information of the land features in a spatial format and in determining, enhancing and monitoring the natural resources of the region. Databases generated using satellite remote sensing techniques over land, atmosphere, and during natural and human-induced hazards have become crucial for management of natural resources, reducing disaster losses, and achieving sustainable development in the region.

Operational Remote Sensing services increased manifolds in the region with the establishment of North Eastern Space Applications Centre (NESAC) in the year 2000 (http://nesac.gov.in). Since inception, NESAC has been providing remote sensing services in generating inventory, planning and developmental activities, and management of natural resources, disasters and dissemination of information and services through geo-web services for NER. The operational remote sensing services provided by NESAC can be broadly divided into three categories viz. natural resource planning and developmental services, disaster risk reduction and early warning services and information dissemination through geo-portal services.

\section{MATERIALS AND METHODS}

\subsection{Study Area}

The study covers all 8 states in the region viz. Arunachal Pradesh, Assam, Manipur, Meghalaya, Mizoram, Nagaland, Sikkim and Tripura (Figure 1).

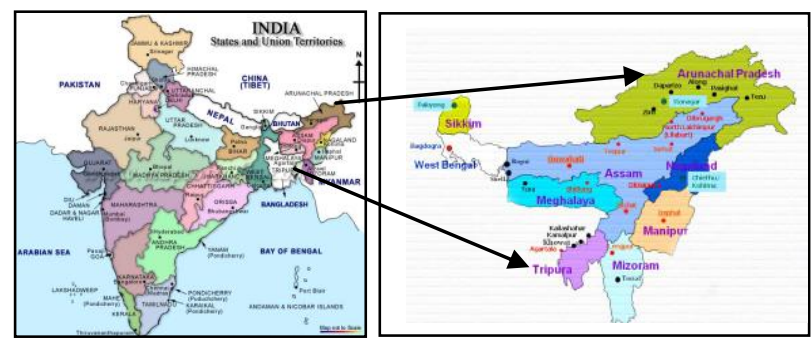

Figure 1. North Eastern Region of India

\subsection{Natural Resource Planning and Developmental Services}

\subsubsection{Remote sensing inputs for preparation of forest} working plan

For scientific development, technological advancements and periodic changes occurring in the forests require its vigilant monitoring, occurrence, nature, structure, composition and diversity. Timber volume and the total growing stock are the key information required for the forest planning and management. All forests are sustainably managed under the prescription of a working plan/scheme. Periodic updation and revision of working plan/scheme is essential to keep pace with the trends and emerging out of forest-people interface.

NESAC has been working in providing the space based inputs for preparing the forest working plans of NER states. The methodology comprises of stratification of study area based on forest type, forest crown density and elevation. The stratified random sampling design which facilitates to capture the maximum variability with equal representation of each stratum using the probability proportionate to area (PPA) method has been followed to distribute the optimum number of sample plots. This has led to minimize the required sampling intensity from $0.1 \%$ to even $0.01 \%$ with an expected accuracy of $90 \%$ at 95\% confidence level. Detailed forest inventory has been carried out from each sample plot of 0.1 ha size. The plot level timber volume is calculated using individual tree level volume equation and average volume for each stratum has been worked out. Subsequently, total growing stock is estimated by extrapolating to the area statistics of each stratum at different administrative level. Similarly, other parameters like stem density, dominant species are also calculated.. Detailed inputs for writing the forest working plan include the detailed land resources, forest type, forest density in spatial format, timber volume and stem density estimates at different girth level under different forest types and forest density, dominant species etc.

\subsubsection{Identifying potential areas for sericulture development}

NE region is having the distinction of producing all four types of natural silk namely Mulberry, Tasar, Eri and Muga. Sericulture production is limited to a few pockets in the region and declining in areas under silkworm food plants is a matter of concern and there is urgent requirement for expansion of sericulture in the culturable wasteland areas (Nageswara Rao, 1991). Potential areas for expansion of sericulture in 41 districts covering all $8 \mathrm{NE}$ states has been mapped using geospatial tools.

Identification of potential areas for sericulture development involved evaluation of land, water resources and climatic requirements for growing silkworm food plants as well as rearing of silk worms (FAO, 1976: Sys, 1993; CSB, 1994). Six parameters of soil viz., drainage, ground water, texture, depth and $\mathrm{pH}$ and two topographic parameters viz, slope and erosion were considered for suitability evaluation. Similarly suitability of climate was described in terms of: (i) temperature (ii) rainfall and (iii) minimal length of growing period.

\subsubsection{Mapping of natural resources}

Mapping of natural resources has been a major and regular activity of the centre for providing critical inputs for various developmental planning. NESAC coordinates these exercises for $\mathrm{NE}$ region. Land use land cover maps are prepared at 1:250000 scale (yearly) and 1: 50000 scale at 5 year intervals following standard classification systems. Mapping of wasteland and degraded lands are prepared at 1:50000 scale and updated at 5 years intervals. Mapping of ground water 
prospect at 1:50000 scale carried out in collaboration with State Remote Sensing Centres, State Universities and State Geology and Mining Departments.

\subsection{Disaster risk reduction}

NESAC has initiated operational services for early warning and post disaster assessment inputs for flood early warning system (FLEWS) using satellite remote sensing,

\subsubsection{Numerical weather prediction}

The centre has given focus on improving the short and medium range weather forecast over NER of India through research on numerical weather prediction, primarily to support the disaster management support program. The WRF (weather research and forecasting) model is being run at NESAC with data assimilation using 4DVAR Hybrid ensemble techniques using a high performance parallel computing system. The model is run at nested domain with $9 \mathrm{~km}$ spatial resolution and 3 hour time steps for NER of India. Data from varied sources like GFS (Global Forecasting System) Prepbufr (Preparation Buffer) surface and upper air observations, Radiances from AMSU-A, MHS, HIRES, AWS data and INSAT 3D wind vector, TRMM and INSAT 3D precipitation estimates, etc are being assimilated. The rainfall forecasts made by the model, being the primary parameter for disaster management, have been compared with AWS measured rainfall for validation. It has been observed that WRF can simulate the rainfall events, most notably the heavy rainfall events (more than $10 \mathrm{~mm}$ per day) to a large extent for most part of the NER. However, predictions for eastern Assam have not been as accurate as that over the remaining parts of NER. These missed rainfall events mostly came in the early hour of the day and studies have been initiated to address the issue.

\subsubsection{Hydrological modeling}

Rainfall-runoff modelling is focused on quantifying the runoff occurrence, without necessarily looking into the processes of runoff generation. Runoff at the spatial and temporal scale for a basin is generally obtained by direct in-situ discharge measurements or indirect techniques involving 'lumped' or 'distributed' hydrologic models. As the conventional method is at times faces constraints with resources and timeframe, etc., hydrologic rainfall-runoff modelling is increasingly used for computing runoff and thereby put into many usages viz., flood simulation, catchment level water management, water balance computation, etc. (Rakhecha and Singh, 2009) After the derivation of peak flood discharges and flow hydrographs, the next step is hydraulic analysis to simulate the river flow and propagation of flood waters in the floodplain or urban catchment. Flood hydraulic modelling is carried out through a 1-D or 2-D flood routing algorithm, based on various modified forms and solutions of the St. Venant's hydrodynamic equations for the accurate spatial distribution of the flow and velocity dynamics. The more complex 2-D models had constraints with data resolutions and other computational issues. Overcoming all these limitations, with the advances in geospatial techniques and computational algorithms, currently 2D flood models are widely used to replicate the flooding process in floodplains and urban environments. Current hydrologic-hydraulic modelling procedures is characterized by three main factors: (i) availability of detailed topographic data, as DEM/DTM, etc and hydrologic data (ii) choice of appropriate flood simulation model and schemes (based on data availability), and (iii) impact of the hydrologic forcing functions on the flood mapping results (design hydrograph, accuracy of the hydro-meteorological data used). In this project, the use of HEC-RAS (Hydrologic Engineering Center's River Analysis System) for riverine floodplains and MIKE FLOOD (Danish Hydraulics Institute package) for urban catchments is recommended (HEC-HMS, 2010). HEC-RAS in short is a one-dimensional steady flow hydraulic model designed to aid hydraulic engineers in channel flow analysis and floodplain determination. HEC-GeoRAS is a tool for ArcGIS for pre and/or post-processing of GIS data and HECRAS results for flood inundation mapping. MIKE FLOOD is a tool that integrates the one-dimensional models MIKE URBAN, MIKE 11 and the two-dimensional model MIKE 21 into a single, dynamically coupled modelling system. This coupled approach enables the best features of both a one dimensional and two dimensional models to be utilized, whilst at the same time avoiding many of the limitations of resolution and accuracy encountered when using MIKE 11, MIKE URBAN or MIKE 21 separately.

\subsubsection{Embankment breach assessment}

Under the FLEWS project, NESAC is also working on post flood embankment breach mapping and monitoring. As a flood control measure, Water Resources Department of Assam has been constructing embankments on either one side or both sides of many of the major rivers. However, due to deforestation in the hill states of north-east India, rate of sedimentation has increased gradually in river Brahmaputra and its tributaries. As a result of continuous sedimentation, rivers of this region are mostly meandering in nature and bank erosion is a common phenomenon for them which leads to embankment breach. In this study using high resolution Cartosat-1 (PAN) imagery, the existing embankment network is mapped and annual breach points are mapped and monitored with the help of Cartosat-1 (PAN), Resourcesat-2 (LISS IV) or RISAT-1 (FRS) imageries prior to the occurrence of monsoon in operational basis. Common elements of image interpretation like tone, texture, pattern, shape, shadow, association were adopted for mapping of breach points along the embankments.

\subsubsection{Forest fire alert system/Assessment}

In NER, there has been close link between forestry and fire since time immemorial due to wide practices of shifting cultivation (locally called Jhum) and it is a seasonal phenomenon in the region that occurs mostly in between February to May every year. Close to $50 \%$ of all forest fires in India occurs in north-east region of India (Bahuguna and Upadhyay 2002) and 95\% forest fires occur due to jhum cultivation practices. Around 14, 3761 forest fire incidences occurred in between January 2001 to April 2014. High aerosol loading and $\mathrm{SO}_{2}$ from biomass burning, associated with shifting cultivation, is reported in NER of India (Badarinath et al., 2004) and a significant correlation was observed between forest fire occurrences and variations in the aerosol 
concentrations in the in NER of India (Kharol et al, 2008). Looking at the severity of forest fire incidences and its associated vulnerability, a detailed analysis of forest fire occurrence and fire vulnerability assessment of the region was carried out. In this study, considering the uniqueness of each of the North Eastern state, the analysis of fire proneness of each state has been assessed independently. Based on the historical fire data collected from different sources from 2001-2013, the nature of fire occurrence with respect to fuel characteristics (vegetation type), topography, proximity to road and settlement, appropriate weightages for each theme in each NE state was decided. With the help of given themes and weightages, Fire Hazard Zonation map has been generated employing Multi Criteria Decision Analysis (MCDA) method in GIS environment. The fire hazard zonation map contain five risk zones categories classified as very high, high, moderate, low and very low.

A forest fire alert system was developed at NESAC under the aegis of North Eastern Regional node for Disaster Risk Reduction (NER-DRR). Although forest fire alerts in the form of fire pixels are given to different parts of the country by different agencies, the uniqueness of this system is that, it doesn't simply reports the fire locations but also do value addition in terms of prioritising fire incidences that could spread based on land use pattern, topographic parameter, meteorological conditions etc. A comprehensive toolbox has been developed in GIS platform to facilitate and automate the whole processing chain, taking MODIS derived fire pixel from NRSC/Bhuvan. During fire season such information is disseminated in near real-time to all the respective State Forest Departments and also uploaded in the public domain in NESAC NER-DRR website (www.nesac.gov.in/nerdrr) in the form of maps and tables containing information of latitude and longitude of fire location, fire occurrence date, state and district name, surrounding LULC, road connectivity, topographic information (slope and aspect), presence of settlements/water bodies and meteorological condition and the corresponding rating of possibility of fire spread. The fire danger rating denoted as severe, high, moderate and low classes for each location is produced within the context of the above thematic information and meteorological data within a buffer of $3 \mathrm{~km}$ for each fire location. Present effort may thus help in taking serious steps to control forest fire and manage it effectively in the region. An attempt has also been made to map the burnt area using Normalized Burned Ratio method with the help of Landsat data for the state of Nagaland and Mizoram. A case study in Mizoram shows the close relationship between forest fire and Jhum cultivation.

\subsubsection{Japanese Encephalitis Early Warning System (JEWS)}

Japanese encephalitis (JE), a mosquito borne viral disease is a serious public health problem in the region, more so in the state of Assam. An early warning system has been developed for the outbreak of JE with the help of remote sensing and GIS in conjunction with the epidemiological studies for three highly JE endemic districts of Assam. Methodology involved is an integrated approach combining characterization of mosquito vector habitats with remote sensing data, establishing relationship of disease onset with variations in meteorological parameters along with the integration of information on hos population and historical disease intensity (Handique et al, 2014). Detailed study was conducted during the period 20032007 to establish the linkages of various factors on the disease outbreak. After validating the model for three years (20082010) at the users' end (District units of National Vector Borne Disease Control Programme and Integrated Disease Surveillance Programme), JEWS has been made operational in three endemic districts of Assam State, viz., Dibrugarh, Sibsagar and Tinsukia.

\subsubsection{Agriculture drought monitoring for the region}

North Eastern States of India climatically falls in Easter Himalayan Region II with high rainfall and prolonged rainy season, medium to high temperature, high relative humidity. Drought, particularly the agricultural drought had been a rare phenomenon in NER of India until last decade. However, of late there has been a substantial increase in frequency of agricultural drought like scenario and their spatial extent in NER. The impact of agricultural drought on crop varies from district to district depending on the type of crops grown and duration (severity) of agricultural drought. Those districts which experienced deficient rainfall for four and more than four consecutive weeks in all four months (June-July-AugustSeptember) may experience total crop losses. A number of indices have been used to measure impact of agricultural drought for this region. The Shortwave Angle Slope Index (SASI) has been used successfully to identify stressed and damaged crops. Since this index is based on SWIR region, SASI is sensitive to moisture and not photosynthetic activity, revealing different dynamics than NDVI (Khanna et.al.2007).

\subsection{Geospatial data dissemination}

The information derived from geographic information system support good governance, better resources planning and overall sustainable development. These space based inputs are very useful for natural resource monitoring and assist in planning activities specially in the North Eastern region as most of the areas in the region has very limited digital and physical connectivity. NESAC has large volume of geospatial data and products at different scales, generated from various projects. The internet based GIS applications are found to be effective medium to disseminate these data effortlessly to millions of remote users (Singh et al, 2012). The necessary computing system for hosting web and geospatial data services has been established the centre. The data services for the districts of NER are being made available for public access through NESAC servers.

Most of the region in the area has very limited or no internet connectivity. According to Ministry of Development of the North Eastern Region estimate, the overall tele-density in Assam is only 10.65 percent compared to the national average of 20 percent and confined to few urban areas. The centre has therefore developed portable standalone applications for dissemination of geospatial data and services at state and district levels. The interactive touch screen based Space Based Information Kiosk (SBIK) system at state level and North Eastern District Resource Plan (NEDRP) portals at district level provides fast access to spatial information and their applications for local level planners for instant decision 
making. Further, the database in the system helps in preparation of accurate detailed project reports. These maps are derived from various satellite imageries and are based on proper scientific methodologies and ground surveys. The information contained in these systems is also being used for monitoring of natural resources and implementation of infrastructure related projects by the higher authorities. This information system follows OGC data policies for interoperability and allows for seamlessly data integration into these standalone systems. The cost effective open source GIS tools and standards were used while developing these applications.

\section{RESULTS AND DISCUSSION}

\subsection{Natural Resource Planning and Developmental Services}

3.1.1 Remote sensing inputs for preparation of forest working plan

Based on the space based inputs provided by NESAC, the respective state forest departments have been writing the forest working plans/schemes which contain the next 10 years prospective plans for sustainable management of the forests under the jurisdiction of the authority for approval by the Ministry of Forest, Environment \& Climate Change, Government of India. Working plans for Meghalaya and Mizoram state has been already approved and at present NESAC is working for the state of Assam and Arunachal Pradesh. The input includes detailed forest canopy density map, quantitative estimation of timber volume (in cubic meters) at different canopy density canopy density <10\% (D1), canopy cover $10-20 \%$ (D2), canopy cover $20-40 \%$ (D3), canopy cover $40-70 \%$ (D4) \& canopy cover $>70 \%$ (D5) and girth classes i.e. girth class $30-60 \mathrm{~cm}(\mathrm{G} 1)$, girth class $60-90$ $\mathrm{cm}(\mathrm{G} 2)$, girth class $90-120 \mathrm{~cm}(\mathrm{G} 3)$, girth class $120-150$ $\mathrm{cm}$ (G4), girth class $150-180 \mathrm{~cm}$ (G5) \& girth class $>180 \mathrm{~cm}$ (G6) for each administrative area under forest department's jurisdiction. An example for estimated timber volume for the state of Meghalaya state is given in Figure 2.

Table 1: Suitable areas for Mulberry host plants in NE states

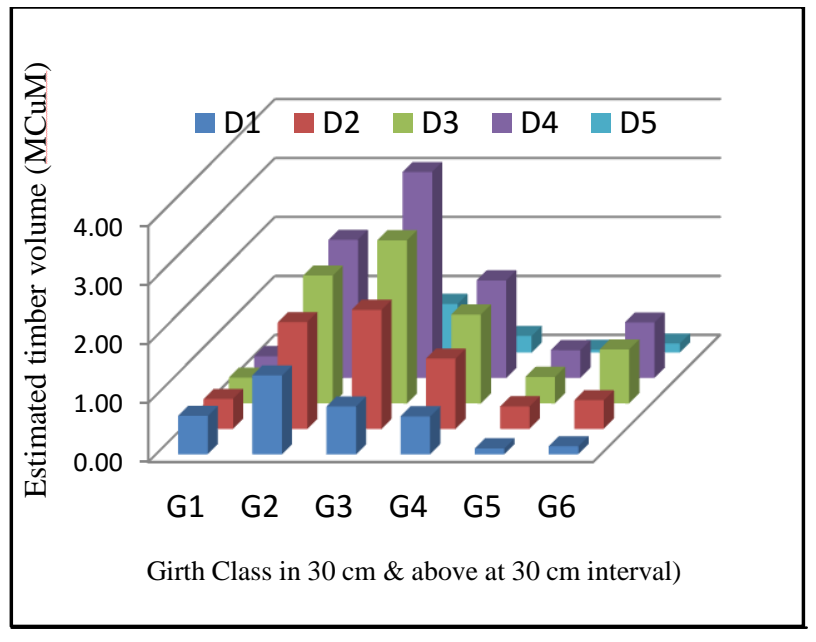

Figure 2. Estimated timber volume of Meghalaya state

3.1.2 Identifying potential areas for sericulture development

The 41 districts selected from NE states, covers a total geographical area of 0.94 million sq $\mathrm{km}$. Among these states, Nagaland has been found to have maximum suitable areas (21.9\% of total geographical area) that can be brought under Mulberry Sericulture. This is followed by Meghalaya (15.8\%) and Sikkim (15.7\%). Due to limitation of physiographic conditions and climate, Arunachal Pradesh is having very limited areas (17242 $\mathrm{Ha}$ in selected 7 districts) that can be brought under sericulture activities (Table 1). A geoportal titled 'Sericulture Information Linkages and Knowledge System' (SILKS) has been conceptualized and developed using Open source GIS as a single window decision support system to provide all the sericulture related information along with spatial information on potential areas for all the selected 108 districts and put in the public domain under the domain name http://silks.csb.gov.in. Within a short span of about two years, the portal has been able to make significant impact particularly in the north eastern region and a number of sericulture expansion activities have been taken up.

\begin{tabular}{|c|c|c|c|c|c|c|c|}
\hline States & $\begin{array}{l}\text { No of } \\
\text { selected } \\
\text { districts }\end{array}$ & $\begin{array}{l}\text { TGA } \\
\text { (Ha) }\end{array}$ & $\begin{array}{l}\text { Highly } \\
\text { suitable } \\
\text { (Ha) }\end{array}$ & $\begin{array}{l}\text { Moderately } \\
\text { suitable } \\
\text { (Ha) }\end{array}$ & $\begin{array}{l}\text { Marginally } \\
\text { suitable } \\
\text { (Ha) }\end{array}$ & $\begin{array}{l}\text { Total } \\
\text { (Ha) }\end{array}$ & $\begin{array}{l}\% \text { of } \\
\text { TGA }\end{array}$ \\
\hline \multirow{2}{*}{$\begin{array}{l}\text { Arunachal Pradesh } \\
\text { Assam }\end{array}$} & 7 & 36981 & 13 & 1908 & 15321 & 17242 & 0.47 \\
\hline & 9 & 32713 & 1169 & 76893 & 232377 & 310439 & 9.49 \\
\hline Manipur & 9 & 22327 & - & - & 67675 & 67675 & 3.03 \\
\hline \multirow{2}{*}{$\begin{array}{l}\text { Meghalaya } \\
\text { Mizoram }\end{array}$} & 2 & 5051 & 13928 & 32381 & 33425 & 79733 & 15.79 \\
\hline & 6 & 18278 & 85598 & 73495 & 17567 & 176660 & 9.67 \\
\hline Nagaland & 5 & 10910 & - & - & 239306 & 239306 & 21.93 \\
\hline Sikkim & 1 & 750 & - & 827 & 5095 & 5922 & 7.90 \\
\hline Tripura & 2 & 4423 & 219 & 17388 & 14745 & 32352 & 7.31 \\
\hline
\end{tabular}




\subsubsection{Mapping of natural resources}

In natural resource management, remote sensing and GIS is mainly used in the mapping process. North Eastern Space Applications Centre has a mandate to generate the baseline database on the natural resources of NER. Accordingly, the different programmes on preparation of natural resource maps like land use land cover at 1:50,000 scale for entire NER for the year 2005-06 \& 2010-11 year, time series database on wastelands of NER under the programme of national Wasteland updation project (2003), national wasteland monitoring project (2005-06), national wasteland change analysis project (2008-09) have been continuously generating for the better developmental planning. The spatial distribution of major land cover classes of NER including wastelands is shown in figures 3 and 4 .

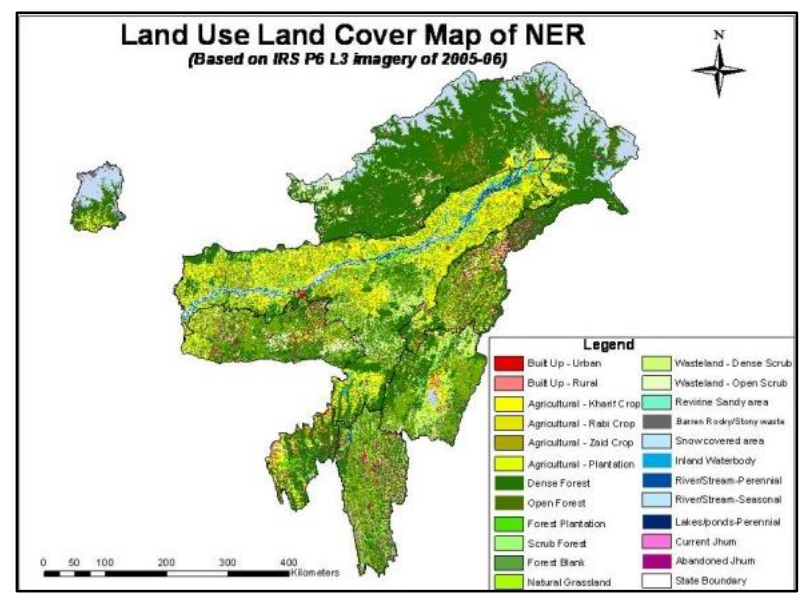

Figure 3. Land Use / Land Cover map of NER

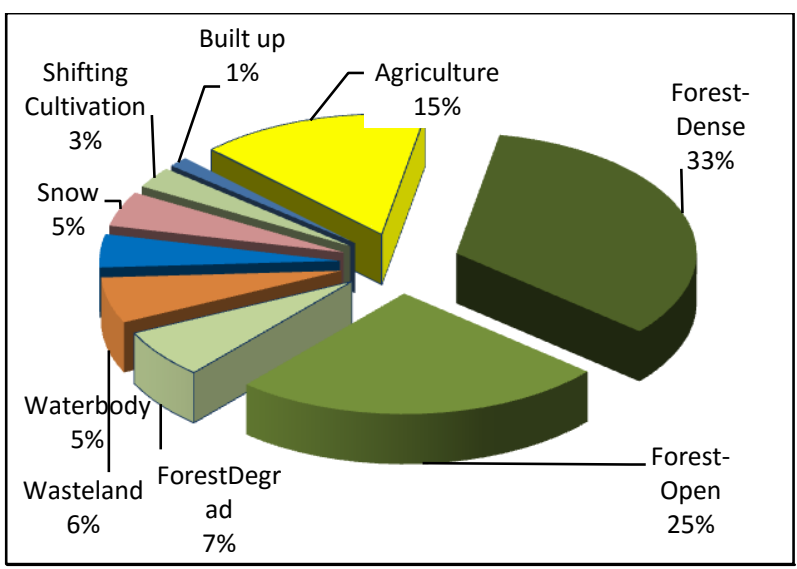

Figure 4. Major land cover classes of NER

\subsubsection{Ground water prospect mapping}

Ground water prospect maps reveals that the variation in landforms as well as rock formations induces local variation in groundwater prospects in NER. Among NE states, the state of Assam is the largest and most potential groundwater reservoirs in the region having three distinct physiographic units namely, Hills and Plateau, Piedmont zones and Plains. In the plain areas having unconsolidated sediments prospect ranges from 200LPM to 800LPM. In the piedmont zone having gravel dominant unconsolidated sediments prospect ranges from 50LPM to 100LPM. In the hills and plateau areas of North Cachar Hills (Dima Hasao), parts of Barak Valley, Southern parts of Tinsukia, Dibrugarh, Sibsagar, Jorhat districts of Assam, prospect ranges from 10LPM to 50LPM. In Karbianlong district of Assam and major parts of Meghalaya, Arunachal Pradesh, Mizoram, Nagaland and Manipur prospect ranges between 10-30 LPM. In these states the prospect is limited to valley portions and along interconnected fractures zones only. The variation in landforms as well as rock formations induces local variation in groundwater prospects in NER. It is also observed that in some areas sustainability of available water is a concern. In order to have required water supply, it is very much essential to take up appropriate scientific measures for management of both surface and subsurface water. This includes construction of proper recharge structures e.g., Nala bunds, check dam, recharge pits etc considering drainage and topography.

\subsection{Disaster risk reduction \\ 3.2.1 Flood Early Warning System}

Flood Early Warning System (FLEWS) is developed and deployed as per request from Assam State Disaster Management Authority (ASDMA), Govt. of Assam from the year 2012 with 14 flood prone districts of Assam. The strength of GIS with hydro-meteorological modelling along with synoptic space based weather monitoring was used for achieving better forecasts. With gradual increase in performance and subsequent requests from Govt. of Assam, 15 flood prone districts were brought under FLEWS in the year 2013 and now all 25 numbers of flood prone districts have been brought under its ambit during the flood season of 2015 .

Operational FLEWS program is further extended from 2015 to 2017 based on specific request by the ASDMA. Further improvement in the hydrological model, updated LULC layer, soil data, improvised routing parameters and use of soil moisture conditions are incorporated into the current model. The effort now has resulted in 39 HEC-HMS models set-up for operational use of FLEWS during 2015. In addition, improvement is also done with regard to increasing the spatial resolution of WRF model forecast to $9 \mathrm{~km}$.

Overall success (considering both absolute and partial success) of the FLEWS alerts have increased from $80 \%$ in 2012 (covering 12 districts) to $92 \%$ in 2015 (covering entire Assam) as shown in Figure 5. In the year 2015, a total of 144 flood alerts were issued, out of which 89 alerts turned out as absolute success (i.e. inundation reported after issue of flood alert) and 43 alerts turned out as partial success (i.e. there was rise in water level above WL/DL of the river but no inundation reported).

Due to high magnitude of flood discharge, channel conveyance is often not adequate and unable to contain stream power/flow momentum for a continuous period of time, which often results 
in embankment breaching frequently in most of the rivers in Assam. In this study, based on the availability of cloud free Resourcesat-2 LISS IV (5.8 spatial resolution) and Cartosat-1 satellite data $(2.5 \mathrm{~m}$ spatial resolution) plugged and unplugged embankment breaches are monitored (Figure 6). This exercise is made operational in 14 flood prone districts of Assam.

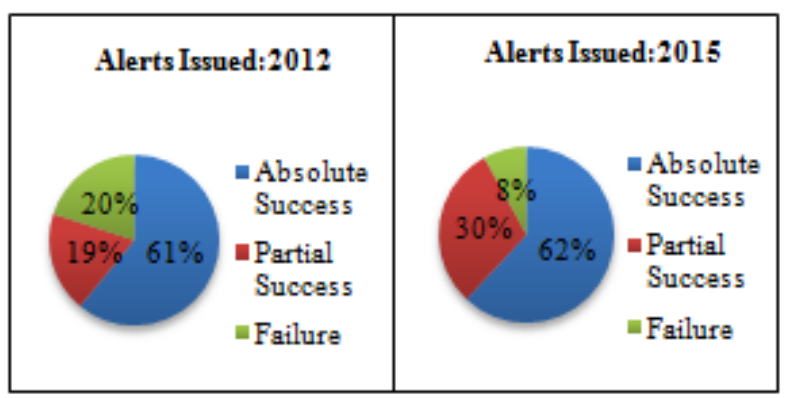

Figure 5. Success of flood alerts for 2012 and 2015

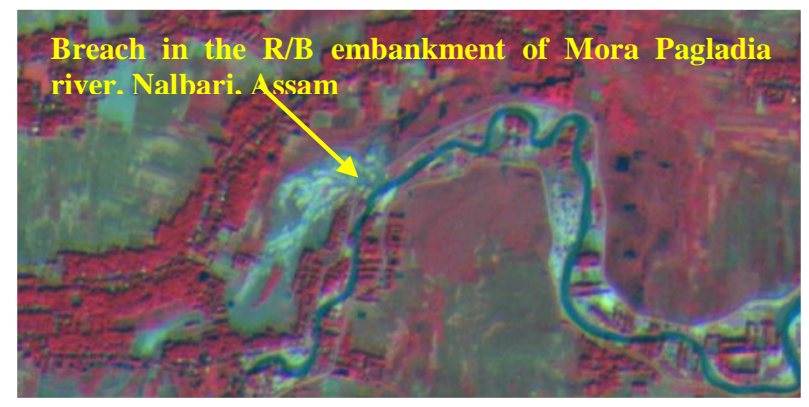

Figure 6. Embankment breach point as seen in Resourcesat-2 (LISS IV) imagery of 2015

\subsubsection{Japanese Encephalitis Early Warning System (JEWS)}

A user friendly open source GIS based software package named Japanese Encephalitis Early Warning System (JEWS) has been developed for use of the concerned health authorities. JEWS spatial modules has inbuilt webGIS tools for displaying and querying of spatial data. The UMN MapServer is used as a GIS engine, PostgreSQL/PostGIS as an object oriented relational database management system (ORDBMS) and GeoServer for creating OGC web services. JEWS can generate forecast on disease onset, intensity and the disease prone villages at least three months ahead of the incidence. The software package has been formally handed over to the concerned health authorities in Assam during a workshop organized in Guwahati, Assam in August 2014 and has been reported to be quite helpful by the concerned departments in taking timely intervention measures for JE control. Spatial distribution of forecasted JE prone villages and actual occurrence of JE cases in Dibrugarh district for the year 2012 is shown in Figure 7. Hands on training on JEWS were provided to the officials of district units of National Vector Borne Disease Control Programme (NVBDCP) and Integrated Disease Surveillance Programme (IDSP) and Joint Directorate of Heath Services in the selected three districts. JE early warning bulletin is also circulated among all these concerned health authorities with a lead time of about 1-2 months prior to onset of the disease.

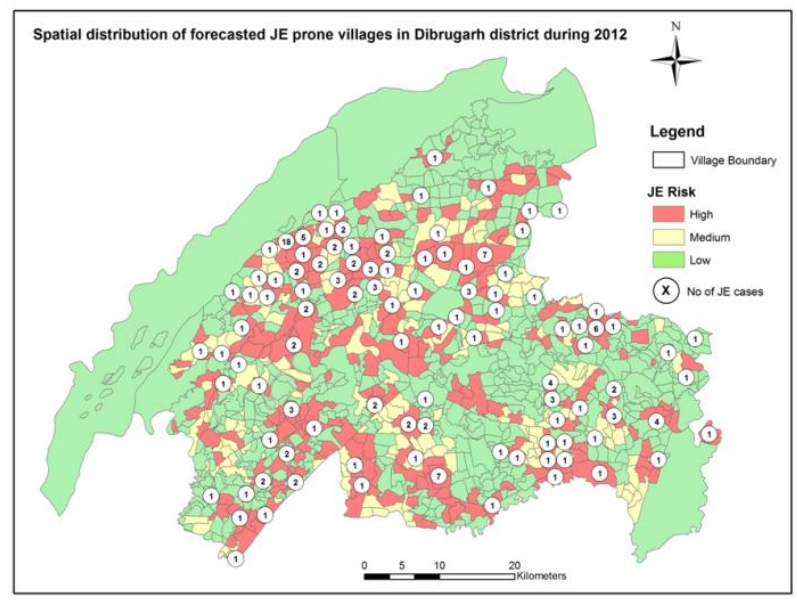

Figure 7. Spatial distribution of forecasted JE prone villages and actual occurrence of JE cases

\subsubsection{Forest fire alert dissemination/ vulnerability zonation}

Trend analysis of fire incidences between the years 2001-2014, year wise fire incidences in NER indicates a decreasing trend. A total of 392 forest fire alert were sent from February to April, 2014 to different forest fire controlling authorities in respective forest departments of $8 \mathrm{NE}$ states through email. Fire vulnerability zonation mapping study shows that in Arunachal Pradesh, out of the total area about $51 \%$ is under moderate vulnerable Zone and $17 \%$ is under high vulnerability zones, whereas in Assam, about $10 \%$ is under high vulnerability zones, and about $21 \%$ of the area has moderate fire vulnerability. In Manipur, 33\% of the forest area is under high vulnerability zones while $39 \%$ in moderate vulnerability. $36 \%$ of the area is under high vulnerability in Meghalaya while $40 \%$ lie in moderate vulnerability zones. In Mizoram, as high as $37 \%$ lie in high vulnerability zone and $48 \%$ in moderate vulnerability zones. Similarly, $43 \%$ of the forest area is under high vulnerability zone in Nagaland, while $36 \%$ comes under moderate vulnerability zone. In Tripura, $53 \%$ is under high and $23 \%$ in moderate vulnerability zone.

Forest fire incidence data of 2014 was analysed with respect to vulnerability zonation map. Results showed that most of the forest fires were observed in moderate and high vulnerability zones in Arunachal Pradesh (50\%, 40\%), Assam (53\% and $35 \%$ ), Manipur (45\% and $43.7 \%$ ) and Mizoram (43.3\% and $42.2 \%)$. In Meghalaya, the maximum fire incidence occurred in high $(52.1 \%)$ vulnerable zone followed by moderate zone $(39.4 \%)$. In Nagaland and Tripura, the maximum fire $53.3 \%$, $59.8 \%$ ) occurred in high vulnerable zone. It is observed that forest fire occurrences in all NE states in the year 2014 corresponds with high and moderate vulnerable zone created for NER based on historical data analysis. Thus, it also indirectly validates the vulnerability zonation map. 


\subsubsection{Agricultural drought monitoring}

The monitoring and assessment of agricultural draught has been initiated since 2009 kharif season as it was one of the most severe summer monsoon rainfall deficient years. In the year 2009 among the NER States, the impact of agricultural drought was severe in Manipur. Since 2009 it has observed that districts of Assam, Meghalaya and Manipur are frequently affected by meteorological as well as agricultural drought. The south-west monsoon rainfall in the month of AugustSeptember may be beneficial to late sown rice crop so areas experienced agricultural drought in the beginning of the season may recovered later.

\subsection{Geospatial data dissemination}

Each standalone portals for North Eastern District Resource Plan (NEDRP) contains 40 geospatial layers, populated in five main information modules, i.e., administrative, infrastructure, natural resources, action plan inputs and disaster management.

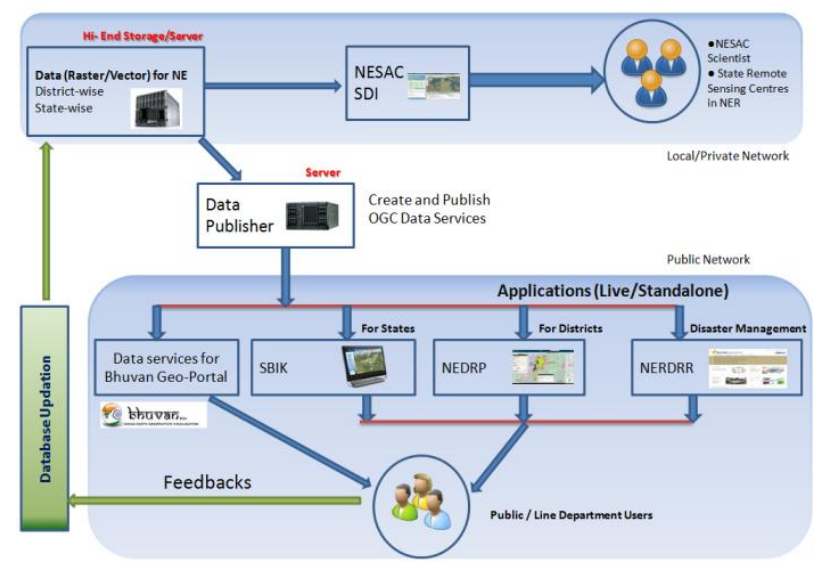

Figure 8. Storage, archival and dissemination of data service

The action plan input layers for land and water resources such as, potential sites for horticulture and afforestation, optimal sites for check dams etc., are generated through multi-criteria spatial analysis. The portal has various GIS tools for map visualisation, navigation, area statistic profile tool and other useful tools such as shortest route finder etc (PS Singh et al, 2015). The portals have been made available for 25 selected districts of NE region with an objective to strengthen the governance policy through geospatial inputs. Further, the data services for these districts have been published and are accessible via ISRO geoportal Bhuvan. The Space Based Information Kiosk (SBIK) portals for states has been installed and deployed in all offices of Chief Secretaries and are being used by many line departments in NE region. The brief diagram depicting storage, archival and dissemination of spatial data in the region is shown in Figure 8.

\section{CONCLUSION}

There has been wide range of earth observation applications in NER and a number of remote sensing services getting operational in the area of natural resources management, disaster risk reduction and dissemination of information and services. NESAC is playing an important role in taking the lead and coordinating with State Remote Sensing Centres, R\&D institutes and user departments in making the operational remote sensing services beneficial to the common people in the region. The current focus of NESAC will be providing regular services in remote sensing applications to natural resources, sericulture development, infrastructure development, disaster management including early warning for floods, forest fires and vector borne diseases, capacity building and training programs (contact based and distance based programs) etc.

\section{ACKNOWLEDGEMENTS}

Contributions from a number of institutes of Department Space viz., National Remote Sensing Centre, Hyderabad Space Applications Centre, Ahmedabad, Indian Institute of Remote Sensing, Dehradun and Remote Sensing Applications Centres in different states in terms providing support and guidance in implementing a large of remote sensing application programmes in north eastern region of the country is duly acknowledged. Contributions and support from ISRO/DOS, DoNER, NEC and Government of India are also thankfully acknowledged.

\section{REFERENCES}

Badarinath, K.V.S., Madhavi Latha, K., Kiran Chand, T.R. Gupta, P.K. Ghosh, A.B., Jain, S.L., Gera, B.S., Singh, R. Sarkar, A.K., Singh, N., Parmar, R.S., Koul, S., Kohli, R., Nath, S., Ojha, V.K., Singh G., 2004. Characterization of aerosols from biomass burning - a case study from Mizoram (Northeast), India. Chemosphere, 54 pp. 167-175.

Bahuguna V.K., Upadhay A., 2002. Forest fires in India: policy initiatives for community participation. International Forestry Review, 4 pp. 122-127.

CSB, 1994. Manual of satellite remote sensing applications for sericulture development. Central Silk Board, Bangalore.

FAO, A Framework for Land Evaluation. Soil Bulletin, 1976, 32. Food and Agriculture Organization. United Nations. Rome, Italy.

Handique, B.K., Khan, S.A, Dutta, P., Sarma, K.K., Chakraborty, K., Goswami, J., Chowdhury, P., Mahanta,J., and Sudhakar, S., 2014. Forecasting spatial distribution of Japanese Encephalitis occurrence-a remote sensing and GIS based study in Assam, India, International Journal of Geoinformatics, 10 (1) pp 1-7.

HEC-HMS User's Manual, Version 3.5, August 2010.

Khanna,S., Orueta, A.P., Whiting, M.L., Ustin, S.L., Riano, D., Litago, J. 2007. Development of Angle Indexes for Soil Moisture Estimation, Dry Matter Detection and Land-cover Discrimination. Remote Sensing of Environment, 109: 154-165. 
Kharol, S.K., Badarinath, K.V.S., Roy, P.S. 2008., Studies on emissions from forest fires using multi-satellite datasets over north east region of india. The International Archives of the Photogrammetry, Remote Sensing and Spatial Information Sciences, 37:473-478 Part B8 Beijing.

Nageswara Rao P.P., Ranganath, B.K. and Chandrashekhar, M.G. 1991., Remote sensing applications in sericulture, Indian Silk, 30 pp. $7-15$

Rakhecha, P.R. and Singh, V.P. 2009., Applied HydroMeteorology. Springer Series, Capital Publishing Company, New Delhi, India.

Singh P. S., Chutia D., Sudhakar S., 2012. Development of a web based gis application for spatial natural resources information system using effective open source software and standards. Journal of Geographic Information System, 4 pp. 261-266.

Singh, P.S., Lyngdoh, R.B., Chutia, D., Saikhom, V., Kashyap B., and Sudhakar S., 2015. Dynamic shortest route finder using pgRouting for emergency management. Applied Geomatics, 7(4) pp. 255-262.

Sys, C., Ranst, V., Debaveye, J. and Beernaert, F., 1993. Land Evaluation Part III, Crop requirements. Agric. pub. , No. 7, ITC, Ghent. 